\title{
ESTUDO DA ARGILA BENTONÍTICA COMO IMPERMEABLIZANTE E SUA APLICAÇÃO EM ATERROS SANITÁRIOS*
}

\section{Resumo}

Brunna Lopes Farace Fabrícia Nunes de Jesus Guedes ${ }^{2}$ Flávia Maria Rodrigues Silveira ${ }^{1}$

A regulamentação brasileira de aterros sanitários estabelece que a disposição de resíduos seja feita no menor espaço possível, desde que os danos à saúde pública e ao meio ambiente sejam os menores possíveis. Devido às irregularidades no tratamento e acomodação de resíduos, é necessário manter e garantir a impermeabilização das bases de aterros. Esse estudo propõe, por meio de uma sistemática revisão, verificar como ocorre a vedação com uso de argila bentonítica, quais os fatores influem na sua ação impermeabilizante, a fim de avaliar a eficácia da sua utilização. Para fundamentar, artigos classificados de acordo com palavraschave, foram ponderados como elegíveis e avaliados. Posteriormente, simulou-se um aterro, por meio do uso de baldes que representam valas. Assim, foram aplicados: uma camada de argila, uma camada de solo e chorume. Visando comparar com exatidão o grau de impermeabilização, foram usadas camadas de argila de espessuras variadas, solo comum e esterilizado. Foram coletadas amostras de chorume bruto e de líquidos percolados para a realização de ensaios e com os resultados obtidos, tabelas foram confeccionadas para facilitar a interpretação. Ao término, constatou-se que uma boa impermeabilização ocorreu com o emprego de 2,0 cm de argila ativada com uso de carbonato de sódio.

Palavras-chave: Impermeabilização; Argila bentonítica; Aterro sanitário.

\section{STUDY OF WATERPROOF CHARACTERISTIC OF BENTONITE CLAY AND ITS APPLICABILITY ON LANDFILL AREAS}

\section{Abstract}

The Brazilian regulation for landfill estabilishes that the disposition of the solid waste must be done in the shorter space possibly, remembering that it shouldn't damage public healthy neather the environment. Due to the amount of irregularities in the Brasilian's system of waste treatment and accommodation, it is really necessary to maintain and guarantee the waterproofing of the landfill foundation. This study aims, throw a great revision, to analyse and to study how and what are the bentonite clay components and properties, which allows and justify its waterproofing action. To support this review, many articles have been considered, and - after a first classification with the keyword - it was ponderated as elegible and evaluated. Afterwards, a landfill was simulated with a tub that represents a 'ditch' where layers of clay, soil and manure were applied. In this process were used different thickness of clay's layers and a commom type of soil sterilized. Then some manure samples and percolated liquids were collected for the trials and the results are shown in tables here. At the end it was observed that it is possible to obtain a good waterproof property with 2,0 centimiters of activated clay and sodium carbonate.

Keywords: Waterproofing; Bentonite clay; Landfill areas.

Graduanda em engenharia de Minas, Universidade do Estado de Minas Gerias, João Monlevade, MG, Brasil.

2 Mestre em Agroquímica, Química. Professora, Faculdade de Engenharia de João Monlevade, Universidade do Estado de Minas Gerais, João Monlevade, MG, Brasil. 


\section{INTRODUÇÃO}

O século $X X$ foi caracterizado pela popularização do modelo de produção fordista que contribuiu para a alteração do modo de consumo social. O consumo se intensificou e a geração de resíduo também, o que é um problema, devido a existência de resíduos em excesso e ao descarte inadequado dos mesmos, o que afeta a qualidade de vida das populações e degrada o ambiente.

É conveniente modificar o modo de acomodar os rejeitos. Para isso, a mudança no estilo de vida e de consumo deve iniciar pela coleta seletiva dos materiais, sua reciclagem e redução da quantidade de resíduos. Essas atitudes, de médio a longo prazo, terão bons resultados. No entanto, a necessidade da sociedade moderna é sanar a problemática de imediato, ou pelo menos, reduzi-la a fim de evitar maiores transtornos. Dessa forma, com o intuito de depositar os resíduos adequadamente sem interferir nas camadas inferiores adjacentes, o atual estudo se propõe a estudar a viabilidade do uso de argila bentonítica para manter a vedação na base do aterro sanitário, uma alternativa que possui considerável duração e objetiva mitigar os impactos socioambientais.

O trabalho tem por finalidade revisar, estudar e debater os principais critérios que influenciam a ação da argila bentonítica como impermeabilizante, sugerindo assim, seu uso eficaz nos aterros sanitários. Para isso, é preciso conhecer e analisar os valores atribuídos aos parâmetros de $\mathrm{pH}$, sólidos sedimentáveis, DBO, DQO, condutividade e presença de Escheríchia Coli.

Sabe-se que a argila é composta por grãos microscópicos, de elevada impermeabilidade. Por esse motivo, possui características particulares, como a facilidade de ser moldada com água e a dificuldade de desagregação. A bentonita pode ser definida como "rocha constituída essencialmente por um argilomineral montmorilonítico (esmectítico), formado pela desvitrificação e subseqüente alteração química" [1]. Este argilomineral controla a permeabilidade pela hidratação, expansão e separação do espaço intercamadas entre as lâminas superpostas, criando caminhos tortuosos, longos e obstruídos para o fluxo.

As placas da montmorilonita são finas, têm feição irregular e tendem a se agrupar durante a secagem. O empilhamento de placas é realizado por forças polares fracas e por forças de Van Der Waals, que segundo Elisângela Barbosa [2] variam inversamente com a distância de separação entre as lamelas.

A elevada afinidade da bentonita com água e sua considerável capacidade de expansão são propriedades que conferem resistência à passagem de água. Em condições confinadas, as partículas expandidas são forçadas entre si para preencher os vazios entre as partículas do solo, constituindo uma barreira contra a passagem do fluxo [3].

Segundo João Meira [4], o grau de deformação da argila, até entrar em rotura, aumenta de modo progressivo até certo valor em função do conteúdo de água. A água funciona como lubrificante que facilita e permite o deslizamento das partículas umas sobre as outras sempre que há tensão superficial.

A sociedade tem ciência de que é preciso mudar o atual modo de acomodação de resíduos para evitar impactos socioambientais. Um dos materiais que tem esse potencial, conforme salientado, é a argila bentonítica, que além de ter alta plasticidade e capacidade de trocar cátions, é pouco permeável, o que permite ser uma alternativa impermeabilizante aplicável em aterros.

A seguir serão detalhados os materiais, métodos, ensaios e analises feitos para verificar a viabilidade da aplicação da argila bentonítica em aterros sanitários. 


\section{MATERIAIS E MÉTODOS}

\subsection{Simulação do Aterro Sanitário e Coleta de Amostras de Solo e Chorume}

Para estudar a viabilidade da aplicação de argila bentonítica como impermeabilizante em aterros sanitários, foi realizada a simulação de um aterro, onde em valas, representadas por baldes que continham em seu fundo furos de 1 $\mathrm{cm}$ de diâmetro, foram aplicadas camadas de argila de espessura variada $(1,0 \mathrm{~cm}$, $1,5 \mathrm{~cm}$ e 2,0 cm). Em seguida, adicionou-se aos baldes solo comum e chorume bruto, ambos coletados no aterro sanitário do Consórcio Público de Gestão de Resíduos Sólidos das cidades Nova Era, João Monlevade, Rio Piracicaba e Bela Vista de Minas, localizado entre João Monlevade e Rio Piracicaba em Minas Gerais.

\subsection{Preparação do Material a ser Empregado nos Ensaios e Esterilização do Solo a Ser Utilização para Fins de Comparação}

Para fins de comparação de resultados sem que houvesse qualquer tipo de influência dos microorganismos presentes no solo coletado no aterro sanitário, foi utilizado, além do solo coletado no aterro também um solo que foi esterilizado a uma temperatura de aproximadamente $110^{\circ} \mathrm{C}$ por 40 minutos. O solo estéril foi depositado nos baldes após secagem da argila e sua quantidade bem como a do chorume despejado foram determinadas obedecendo as proporções existentes no aterro sanitário, seguindo as informações obtidas na revisão de literatura e na pesquisa de campo realizada.

A representação do experimento simulando as condições do aterro sanitário foi ilustrada na figura 1.

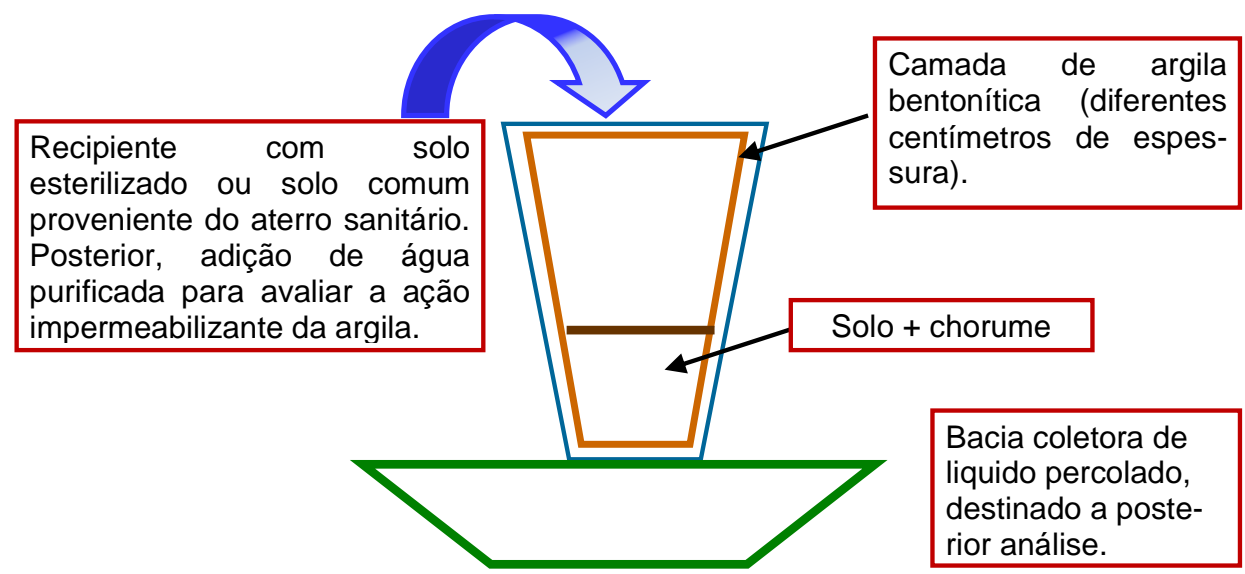

Figura 1. Esboço representativo da simulação de aterro sanitário realizada.

Antes de aplicar a argila em pó nos baldes hidratou-se a mesma com água (figura 2). Sabe-se que com o manuseio abrupto, surgem nuvens de pó, porém a quantidade de pó perdida é mínima, por isto durante 30 minutos ininterruptos, misturou-se de maneira cuidadosa a argila bentonítica em pó, à água até que a mescla adquirisse certa consistência. Após o descanso de 4 horas, repetiu-se 0 processo e em seguida fez-se a sua aplicação nos baldes. 


\subsection{Utilização de Água Purificada, Estudo do Escoamento e Avaliação da Impermeabilização do Argilomineral}

Pelo fato de a bentonita ter uma hidratação diferenciada dependendo da natureza do líquido em contato, cada vala independente de conter solo esterilizado, recebeu 3,5L de água ultrapurificada. Para obtenção dessa água foi realizado o tratamento por osmose reversa, que de acordo com Isabel Claas (1994) [5], é um processo que permite a remoção dos sólidos dissolvidos de um determinado efluente por meio da filtração através de uma membrana semipermeável, sob pressão superior à exercida pela pressão osmótica dos sólidos dissolvidos no líquido a ser filtrado. O uso desse tipo de água em particular é o mais indicado por impedir a influência da própria água nos ensaios realizados, já que o processo de osmose reversa é capaz de separar a água de seus contaminantes, o que possibilita obter um resultado mais exato e real. Após este processo de purificação da água, a mesma foi imediatamente despejada sobre o solo para que não houvesse alteração nos ensaios analíticos e após o escoamento, foi coletada e destinada à analise laboratorial. Desta forma, a quantidade de água despejada na hidratação foi suficiente para encharcar o solo e gerar um escoamento em quantidade suficiente para ser analisada.

\subsection{Coleta e Envio do Chorume Bruto e dos Líquidos Percolados Advindos das Valas de $1,5 \mathrm{~cm}$ de Argila ao Laboratório Terceirizado}

O chorume bruto diretamente coletado no aterro sanitário foi destinado a realização de ensaios em laboratórios terceirizados e especializados para avaliação da presença de bactérias Escheríchia Coli e verificação dos valores para os parâmetros como $\mathrm{pH}$, sólidos sedimentáveis, DBO, DQO e condutividade.

Quanto aos líquidos resultantes da percolação após o despejo da água, este foi coletado da vala que continha solo comum e da que continha solo esterilizado, ambas com $1,5 \mathrm{~cm}$ de espessura de argila em seu interior. O material foi armazenado em recipientes etiquetados, esterilizados, hermeticamente fechados e, posteriormente, acondicionados em caixas apropriadas, seguindo todos os procedimentos necessários adequados à amostragem, sendo enviado ao laboratório terceirizado anteriormente citado. Esse material percolado foi analisado com base nos mesmos seis critérios adotados para análise do chorume bruto. Tais estudos foram executados dentro do prazo de validade, segundo a metodologia da $21^{\text {a }}$ edição do livro Standard Methods for the Examination of Water and Wastewater.

\subsection{Recolhimento dos Líquidos Percolados Provenientes das Valas de 2,0 cm de Espessura de Argila e Posterior Análise}

Foram feitas novas análises e o material analisado foi o líquido que escoou coletado da vala de solo esterilizado e da vala de solo comum, porém desta vez as valas tinham camadas de 2,0 cm de argila bentonítica em seu interior. Decidiu-se, por meio de considerações e estudos teóricos, avaliar nesse segundo momento, as características do material procedente das valas com maior espessura de argila para verificar o grau e forma de ocorrência da impermeabilização nesta situação. Por se considerar a questão de custo/benefício em termos de tempo e gastos, conseguiu-se contratar um novo laboratório terceirizado, também especializado, que realizou as análises em menor tempo que o laboratório anterior. Os ensaios executados foram exatamente os mesmos para que a comparação e, a partir dela, a interpretação e 
inferência de conclusões fosse confiável. Além disso, as análises apresentavam conformidade com a metodologia da 21ํㅡ edição do livro Standard Methods for the Examination of Water and Wastewater.

\subsection{Processo de Ativação da Argila Bentonítica com Uso de Carbonato de Sódio}

De posse dos resultados das análises e com objetivo de otimizá-los, novamente recorreu-se à literatura especializada. A partir deste novo estudo teórico, realizou-se a ativação da argila bentonítica por meio do tratamento químico com uso de carbonato de sódio $\left(\mathrm{Na}_{2} \mathrm{CO}_{3}\right)$, visto que a argila bentonítica apresenta predominância de íons cálcio, ocorrendo troca catiônica e mudança dos cátions interlamelares de $\mathrm{Ca}^{2+}$ por $\mathrm{Na}^{+}$, sendo que o íon $\mathrm{Na}^{+}$hidratou-se mais que o $\mathrm{Ca}^{2+}$, conforme mostrado a seguir:

$$
\text { Bentonita } \mathrm{Ca}^{2+}+\mathrm{Na}_{2} \mathrm{CO}_{3}=\text { Bentonita } \mathrm{Na}^{+}+\mathrm{CaCO}_{3}
$$

Repetiu-se o mesmo processo para simulação do aterro sanitário, porém, desta vez, borrifando na argila bentonítica aplicada em cada vala, uma solução de $250 \mathrm{~mL}$ de carbonato de sódio com água.

\subsection{Recolhimento dos Líquidos Percolados das Valas de 2,0 cm de Espessura de Argila e Envio ao Laboratório Terceirizado}

Das valas de $2,0 \mathrm{~cm}$ de argila tanto de solo comum quanto de solo esterilizado, foram coletados os líquidos escoados destinados a analises a serem feitas pelo Laboratório Terceirizado Especializado. A coleta do material foi feita com os devidos cuidados para não comprometer as etapas seguintes de avaliação do estudo. A metodologia utilizada foi a mesma que a dos estudos laboratoriais anteriores, $21^{\underline{a}}$ edição do livro Standard Methods for the Examination of Water and Wastewater e o prazo de validade para realização dos ensaios foi obedecido de modo adequado.

\subsection{Comparação entre os Dados e Interpretação dos Resultados:}

A partir da montagem da simulação do aterro sanitário e considerando os seis critérios avaliados durante esse estudo foram obtidos vários resultados que foram devidamente analisados e discutidos.

\section{RESULTADOS E DISCUSSÃO}

\subsection{Hidratação e Expansão da Argila}

Tendo em vista que a função principal da argila é servir, nesse caso, como barreira hidráulica, a sua hidratação e expansão são parâmetros importantes para o seu bom desempenho. Por esse motivo antes de aplicada, a argila em pó foi ativada com água. Isso se justifica, já que a bentonita contém pequenos poros, o que implica na necessidade de pequenas dilatações para ser capaz de servir como barreira.

A bentonítica possui partículas muito pequenas de silicatos de alumínio hidratado e apresenta um empilhamento de lamelas, exibindo alta capacidade de troca de cátions. "A capacidade de troca catiônica é uma propriedade muito importante das argilas, pois pela troca de cátions pode-se modifica-las quimicamente, influindo diretamente sobre suas propriedades físico-químicas. A hidratação dos cátions 
interlamelares gera o acúmulo de moléculas de água no espaço interlamelar das argilas e seu consequente inchamento, aumentando as distâncias interlamelares" [6].

\subsection{Ativação da Argila com Uso do Carbonato de Sódio $\left(\mathrm{Na}_{2} \mathrm{SO}_{4}\right)$}

Inicialmente a argila havia sido apenas hidratada com água, porém baseando-se na leitura de diversos artigos sobre a eficiência do uso da argila ativada como material de vedação resolveu-se testar a ativação da argila com o emprego de carbonato de sódio. Nesse processo, a bentonita passa de cálcica para sódica e isso é fundamental para sua eficiência, pois as bentonitas sódicas adsorvem água de modo contínuo, inchando e aumentando seu volume até a completa esfoliação de suas lamelas em água, enquanto, as bentonitas cálcicas não se esfoliam em suspensão aquosa, o inchamento que ocorre é pequeno e as partículas precipitam rapidamente. Embora a ativação de montmorilonitas cálcicas com carbonato de sódio não permita obter especificamente as propriedades da bentonita sódica natural, devido ao maior grau de pureza que essa apresenta, esse método possibilita a obtenção de um material com características intermediárias entre a bentonita ativa e a não ativada.

O uso específico do carbonato de sódio se deve ao fato de que "a quantidade de filtrado obtido em lama tixotrópica é influenciada pela presença do íon sódio nas camadas octaédricas da argila, por isso a necessidade de ativar essas argilas com carbonato de sódio, melhorando também outras propriedades como: inchamento e viscosidade" [7].

\subsection{Obtenção de Resultados e sua Interpretação}

Feita a simulação do aterro, executou-se os ensaios laboratoriais seguindo a mesma metodologia para cada parâmetro.

- 1 ${ }^{\text {a }}$ análise: chorume bruto coletado no aterro;

- 2 $2^{\mathrm{a}}$ análise: chorume após tratamento proveniente da vala que continha solo comum e da vala que continha solo esterilizado, ambas com 1,5 cm de argila.

- 3 a analise: chorume após tratamento proveniente da vala que continha solo comum e da vala que continha solo esterilizado, ambas com 2,0 cm de argila.

- 4a analise: chorume após tratamento proveniente da vala que continha solo comum e da vala que continha solo esterilizado, ambas com 2,0 cm de argila ativada com carbonato de sódio.

\subsubsection{Análise do chorume bruto}

As tabelas 1 e 2 expõem os resultados dos ensaios realizados com o chorume bruto após coleta no aterro sanitário.

Tabela 1. Resultados dos parâmetros analidos para chorume bruto

\begin{tabular}{lccc}
\hline \multicolumn{1}{c}{ Parâmetros } & Padrão & Unidades & Resultado \\
\hline $\mathrm{pH}$ & 6 a 9 & - & 8,4 \\
Sólidos Sedimentavéis & Até 1 & $\mathrm{~mL} / \mathrm{L}$ & 0,2 \\
$\mathrm{DBO}$ & Até 60 & $\mathrm{mg} / \mathrm{L}$ & 604,0 \\
$\mathrm{DQO}$ & Até 180 & $\mathrm{mg} / \mathrm{L}$ & 4734 \\
Condutividade & - & - & 17971,00
\end{tabular}

Padrão estabelecido pela Deliberação Normativa Conjunta COPAM/CERH №1 de 05 de Mai o de 2008 - Efluentes. 
Tabela 2 Resultados quanto à presença E. Coli para chorume bruto

\begin{tabular}{cccc}
\hline Parâmetros & Padrão & Unidade & Resultado \\
\hline Bactérias Escheríchia coli & - & MNP/100mL & 12 \\
\hline *Deliberação Normativa Conjunta COPAM/CERH-MG №1 de 05 de Maio de 2008 - Efluentes & \\
\hline \multicolumn{2}{c}{ Grau de confiança de 95,54\% com fator de abrangência K=2. } &
\end{tabular}

De acordo com a Deliberação Normativa Conjunta COPAM/CERH №01 de 05 de Maio de 2008 para efluentes [8], para os parâmetros particulares de pH e sólidos sedimentáveis o chorume bruto encontra-se dentro do padrão esperado. Porém, pelo fato de os valores obtidos para DBO e DQO estarem expressivamente elevados, conclui-se que o chorume não está, de modo geral, em conformidade com o padrão de lançamento descrito no capítulo $V$ da normativa. Dessa forma a impermeabilização deve ser significativa para não permitir a passagem do conteúdo contaminado.

O elevado valor de DBO encontrado na amostra de chorume bruto sinaliza a alta quantidade de matéria orgânica presente no meio, o que possivelmente levou a decomposição anaeróbia e comprometeu a qualidade do chorume analisado. Como observado na tabela, o valor de DQO é superior ao de DBO e isso é esperado, tendo em vista que também se oxidam por este método as substâncias não biodegradáveis. De acordo com estudos conduzidos por Cristina Sisinno e Josino Moreira (1996) [9], os elevados valores de DQO e DBO sugerem que o chorume seja, na realidade, constituído por uma mistura daqueles produzidos por lixos em diferentes estados de decomposição.

A relação entre DBO e DQO é indicativa da qualidade da água, já que avalia a biodegrabilidade do tratamento do efluente. A razão entre esses dados de acordo com a tabela acima é de aproximadamente 0,13 , o que refere a um efluente de difícil tratamento biológico, uma vez que o valor obtido é inferior a 0,2.

\subsubsection{Análise do chorume após tratamento da vala com $1,5 \mathrm{~cm}$ de argila}

A tabela 3 mostra os resultados das analises a partir do chorume após tratamento proveniente da vala que continha solo comum e da vala que continha solo esterilizado, ambas com 1,5 cm de argila.

Tabela 3. Resultados analíticos para os percolados

\begin{tabular}{lcc}
\hline \multicolumn{1}{c}{ PARÂMETROS } & $\begin{array}{c}\text { CHORUME APÓS } \\
\text { TRATAMENTO }\end{array}$ & $\begin{array}{c}\text { CHORUME APÓS } \\
\text { TRATAMENTO }\end{array}$ \\
\hline & Vala com solo comum & Vala com solo esterilizado \\
\hline Escheríchia Coli & $610000 \mathrm{MNP} / 100 \mathrm{~mL}$ & $92000 \mathrm{MNP} / 100 \mathrm{~mL}$ \\
pH & 8,3 & 7,7 \\
Sólidos Sedimentáveis & $10 \mathrm{~mL} / \mathrm{L}$ & $4 \mathrm{~mL} / \mathrm{L}$ \\
DBO & $4,6 \mathrm{mg} / \mathrm{L}$ & $293 \mathrm{mg} / \mathrm{L}$ \\
DQO & $335 \mathrm{mg} / \mathrm{L}$ & $1105 \mathrm{mg} / \mathrm{L}$ \\
Condutividade & 2176 & 3851 \\
\hline Grau de confiança de 95,54\% com fator de abrangência K=2. & \\
*Deliberação Normativa Conjunta COPAM/CERH-MG №1 de 05 de Maio de 2008 - Efluentes \\
Padrão estabelecido pela Deliberação Normativa Conjunta COPAM/CERH №01 de 05 de Mai o de 2008 - Efluentes.
\end{tabular}

Tendo em vista que as condições de avaliação e a espessura da camada de argila bentonítica eram as mesmas para ambas as valas, a diferença existente entre os 
valores observados se deve à distinção da natureza dos solos presentes em cada vala. A presença de solo esterilizado em uma das valas impede a influencia do solo nos resultados obtidos, o que possibilita ter resultados mais próximos do real.

Nos dois dados obtidos o líquido percolado não está em conformidade com o padrão estabelecido pela Deliberação Normativa Conjunta COPAM/CERH MG №01 de 05 de Maio de 2008 - Cap.V. Para o chorume após tratamento da vala com solo comum, isso é explicado pelos elevados valores de sólidos sedimentáveis e DQO enquanto que para o proveniente da vala com solo esterilizado se justifica nos valores consideráveis de sólidos sedimentáveis, DBO e DQO.

De acordo com a tabela de resultados obtidos, há uma pequena variação do valor de $\mathrm{pH}$ do chorume bruto e do $\mathrm{pH}$ do chorume proveniente da vala que apresentava solo comum, ambos se apresentaram ácidos. Para esse parâmetro, o valor que apresenta maior diferença aos demais que, porém permanece sendo ácido, é o correspondente ao chorume derivado da vala de solo esterilizado.

Outro fator importante é o grande aumento da presença de E. Coli comparando o chorume bruto (tabela 1) a ambos os chorumes após o tratamento (tabela 2). Isso pode ser explicado com base no tempo decorrido entre a coleta, o ensaio e a realização da análise que, provavelmente, propiciou a proliferação de bactérias no meio, já que as condições de umidade, $\mathrm{pH}$ e temperatura eram favoráveis para permitir tal crescimento.

Observando na tabela acima os valores relativos à presença de E. Coli para os chorumes após tratamento constata-se menor valor atribuído ao chorume proveniente da vala que continha solo esterilizado, o que é justificável devido o processo de esterilização que, por eliminar a vida microbiológica existente no solo, impede a influência deste nos resultados.

\subsubsection{Análise do chorume após tratamento da vala com $2,0 \mathrm{~cm}$ de argila}

Os valores dos ensaios feitos com uso do chorume após tratamento proveniente da vala que continha solo comum e da vala que continha solo esterilizado, ambas com 2,0 cm de argila são apresentados na tabela 4 .

Tabela 4. Resultados analíticos para chorume percolado

\begin{tabular}{lcc}
\multicolumn{1}{c}{ PARÂMETROS } & $\begin{array}{c}\text { CHORUME APÓS } \\
\text { TRATAMENTO }\end{array}$ & $\begin{array}{c}\text { CHORUME APÓS } \\
\text { TRATAMENTO }\end{array}$ \\
& Vala com solo comum & Vala com solo esterilizado \\
\hline Escheríchia Coli & $11 \mathrm{UFC} / 100 \mathrm{~mL}$ & AUSENTE \\
pH & 7,32 & 7,11 \\
Sólidos Sedimentáveis & $24 \mathrm{~mL} / \mathrm{L}$ & $6,5 \mathrm{~mL} / \mathrm{L}$ \\
DBO & $28,9 \mathrm{mg} / \mathrm{L}$ & $64,3 \mathrm{mg} / \mathrm{L}$ \\
DQO & $381 \mathrm{mg} / \mathrm{L}$ & $192 \mathrm{mg} / \mathrm{L}$ \\
Condutividade & $1029,5 \mu \mathrm{SS} / \mathrm{cm}$ & $653,4 \mu \mathrm{S} / \mathrm{cm}$ \\
Temperatura & $21,8^{\circ} \mathrm{C}$ & $22^{\circ} \mathrm{C}$ \\
\hline
\end{tabular}

$\mathrm{Na}$ situação apresentada, não foi detectada presença de Escheríchia Coli no chorume após tratamento proveniente da vala com solo esterilizado, enquanto para o da vala com solo comum o valor é muito inferior ao correspondente na tabela 2. Isso permite afirmar que a impermeabilização nessa situação, em que se utiliza maior espessura da camada de argila, foi mais eficaz, uma vez que os contaminantes ficaram retidos, como proposto no estudo do presente projeto. 
A condutividade auxilia também na explicação da satisfatória eficiência em vedação, pois verificando os resultados da tabela 2 e 3, nota-se redução expressiva do valor de condutividade para ambos os chorumes coletados. Isso ocorreu devido ao fato de a bentonita absorver mais água, já que possui maior espessura, propiciando uma expansão de modo mais significativo, o que permitiu a existência de uma barreira de argila mais resistente e impermeável, atendendo ao objetivo do estudo. Essa barreira foi a responsável por impedir a passagem dos contaminantes e contribuir para 0 acentuado decréscimo da condutividade hidráulica, que diminui pela influência do aumento da matéria orgânica presente no meio, que auxilia na retenção de água nos solos e é responsável, em grande parte, pelo aumento da capacidade de troca catiônica do solo. Com o tempo, naturalmente houve aumento da matéria orgânica presente no chorume, já que se observa aumento em sólidos sedimentáveis.

\subsubsection{Análise do chorume após tratamento da vala com $2,0 \mathrm{~cm}$ de argila ativada com carbonato de sódio}

A tabela 5 exibe os resultados da analise laboratorial na qual se utilizou chorume após tratamento proveniente da vala que continha solo comum e da vala que continha solo esterilizado, ambas com 2,0 cm de argila ativada com $\mathrm{Na}_{2} \mathrm{CO}_{3}$.

Tabela 5. Resultados analíticos para o líquido percolado

\begin{tabular}{lcc}
\hline \multicolumn{1}{c}{ PARÂMETROS } & $\begin{array}{c}\text { CHORUME APÓS } \\
\text { TRATAMENTO }\end{array}$ & $\begin{array}{c}\text { CHORUME APÓS } \\
\text { TRATAMENTO }\end{array}$ \\
\hline & Vala com solo comum & Vala com solo esterilizado \\
\hline Escheríchia Coli & AUSENTE & AUSENTE \\
pH & 7,71 & 7,7 \\
Sólidos Sedimentáveis & $110 \mathrm{~mL} / \mathrm{L}$ & $15 \mathrm{~mL} / \mathrm{L}$ \\
DBO & $6,9 \mathrm{mg} / \mathrm{L}$ & $2,1 \mathrm{mg} / \mathrm{L}$ \\
DQO & $59 \mathrm{mg} / \mathrm{L}$ & $83 \mathrm{mg} / \mathrm{L}$ \\
Condutividade & $10422 \mu \mathrm{S} / \mathrm{cm}$ & $5563 \mu \mathrm{S} / \mathrm{cm}$ \\
Temperatura & $23,4^{\circ} \mathrm{C}$ & $23,4^{\circ} \mathrm{C}$ \\
\hline
\end{tabular}

De acordo com a tabela 5, nota-se ausência de $\mathrm{E}$. Coli o que é relevante, pois a presença de contaminantes na água revela o risco do seu consumo e a necessidade de adotar medidas de controle para melhorar sua qualidade, visando não comprometer sua utilização bem como a contaminação do meio. Além disso, permite afirmar que a impermeabilização foi efetivamente conseguida com sucesso, já que não há contaminantes fecais.

Acredita-se que a ativação da argila bentonítica com uso de uma solução feita com carbonato de sódio e água foi essencial para conseguir ausência de E. Coli, pois esse foi o único procedimento diferente adotado entre os ensaios das amostras coletadas para a última análise. Acredita-se, ainda, que o processo de ativação fez com que a argila adsorvesse água continuamente e assim aumentasse seu volume até a total esfoliação de suas lamelas em água, o que satisfez aos objetivos propostos neste projeto.

É importante ainda mencionar que segundo Cristina Sisinno (1996) [10], a redução de acidez, assim como dos valores de DBO e DQO que na tabela 4 são altos e tendem, em geral, segundo a tabela 5, a decrescer expressivamente, devido à ocorrência da biodegradação da matéria orgânica. 


\section{CONCLUSÃO}

Foi possível obter uma boa impermeabilização quando a argila bentonítica foi ativada com o uso de uma solução feita com água e carbonato de sódio e foi empregada em espessura de $2,0 \mathrm{~cm}$, satisfazendo, dessa forma, aos objetivos propostos pelo presente trabalho.

A elevada capacidade de sorção juntamente a condutividade hidráulica evidencia a capacidade de impermeabilização do solo ao material percolado. É preciso mencionar que o bom desempenho da argila como barreira impermeabilizante depende da sua natureza, da presença de um detalhado projeto executivo, da correta instalação e da adequada fiscalização da qualidade de impermeabilização.

\section{Agradecimentos}

Agradeço a Fundação de Amparo a Pesquisa do Estado de Minas Gerais, fonte de fomento do projeto de Iniciação Científica 06/2013 que instigou a redação deste trabalho e, também, a Faculdade de Engenharia da Universidade do Estado de Minas Gerais, por permitir e disponibilizar espaço físico para o desenvolvimento das pesquisas e consulta ao acervo bibliográfico. Á orientadora, que se mostrou muito presente em auxiliar e acompanhar os estudos, além de sanar as dúvidas.

\section{REFERÊNCIAS}

1 Ross, C.S. \& Shannon, E.V. Minerals of Bentonite and Related Clays and Their Physical Properties. Journal of American Ceramic Society 9, 77-96 (1926).

2 Barbosa, E. M. C. Materiais mistos nanoestruturados baseados em argilas bentonita e cobalto coloidal. 2009. [Acesso em: 05 de mar. 2013]. Dissertação de Mestrado, 56 páginas. Disponível em http://tede.unicentro.br/tde_arquivos/1/TDE-2009-0213T071217Z-15/Publico/elisangela_otimizada.pdf.

3 Camargo, Karina. Avaliação da condutividade hidráulica e da resistência ao cisalhamento de misturas solo-bentonita: estudo de caso de um aterro sanitário localizado em Rio Grande (RS). 2012. [Acesso em: 06 de mar. 2013]. Disponível em http://www.teses.usp.br/teses/disponiveis/18/18132/tde-18062013-110028/es.php.

4 Meira, João. Argilas: o que são, suas propriedades e classificação. Comunicações técnicas. 7 páginas. 2001. [Acesso em: 06 de mar. 2013]. Disponível em http://www.visaconsultores.com/pdf/VISA_com09.pdf.

5 CLAAS, Isabel Cristina; MAIA, Roberto A.M. Manual básico de resíduos industriais de curtume. Porto Alegre: SENAI/RS, 1994. 664 p. [Acesso em: 07 de mar. 2013]. Disponível em http://www.bdpa.cnptia.embrapa.br/busca?b=ad\&id=524321\&biblioteca=vazio\&busca= autoria:\%22M.\%22\&qFacets=autoria:\%22M.\%22\&sort=\&paginacao=t\&paginaAtual=27 28.

6 Teixeira-Neto, E.; Teixeira-Neto, A. A. Modificação química de argilas: desafio científicos e tecnológicos para obtenção de novos produtos com maior valor agregado. Química Nova. V.32, 2009. [Acesso em: 08 de mar. 2013]. Disponível em http://www.scielo.br/scielo.php?script=sci_arttext\&pid=S0100-40422009000300023.

7 Claudino, M. D. R.; Silva, M. D.; Silva, J. N.; Junior, S. C. B.; Monteiro, G. S. Avaliação do potencial de impermeabilização de argilas bentonítica natural (cálcica) e ativada (sódica) oriundas do município de Boa Vista - PB. Associação Brasileira de Química, 2007.

8 Deliberação Normativa Conjunta COPAM/CERH-MG n 01, de 05 de maio de 2008. [acesso em 14 de março. 2013] Disponível em: http://www.siam.mg.gov.br/sla/download.pdf?idNorma=8151. 
9 Sisinno, C. L. S.; Moreira, J. C. Avaliação da contaminação e poluição ambiental na área de influência do aterro controlado do Morro do Céu, Niterói, Brasil. Cad. Saúde Pública, Rio de Janeiro, 1996. [Acesso em: 08 de mar. 2013]. Disponível em http://www.scielo.br/scielo.php?pid=S0102-311X1996000400010\&script=sci_arttext.

10 Sisinno, C. L. S.; Moreira, J. C. Avaliação da contaminação e poluição ambiental na área de influência do aterro controlado do Morro do Céu, Niterói, Brasil. Cad. Saúde Pública, Rio de Janeiro, 1996. [Acesso em: 08 de mar. 2013]. Disponível em http://www.scielo.br/scielo.php?pid=S0102-311X1996000400010\&script=sci_arttext. 